\title{
Anomalies in the carbonate system of Red Sea coastal habitats
}

\author{
Kimberlee Baldry $^{1, \mathrm{a}}$, Vincent Saderne ${ }^{1}$, Daniel C. McCorkle ${ }^{2}$, James H. Churchill ${ }^{2}$, Susana Agusti ${ }^{1}$, and \\ Carlos M. Duarte ${ }^{1}$ \\ ${ }^{1}$ Red Sea Research Center and Computational Bioscience Research Center, King Abdullah University of Science and \\ Technology (KAUST), Thuwal, 23955, Saudi Arabia \\ ${ }^{2}$ Woods Hole Oceanographic Institution (WHOI), Woods Hole, Massachusetts 02543, USA \\ ${ }^{a}$ currently at: Institute of Marine and Antarctic Studies, University of Tasmania, Hobart 7000, Australia
}

Correspondence: Kimberlee Baldry (kimberlee.baldry@utas.edu.au)

Received: 23 May 2019 - Discussion started: 3 June 2019

Revised: 3 December 2019 - Accepted: 13 December 2019 - Published: 29 January 2020

\begin{abstract}
We use observations of dissolved inorganic carbon (DIC) and total alkalinity (TA) to assess the impact of ecosystem metabolic processes on coastal waters of the eastern Red Sea. A simple, single-end-member mixing model is used to account for the influence of mixing with offshore waters and evaporation-precipitation and to model ecosystemdriven perturbations on the carbonate system chemistry of coral reefs, seagrass meadows and mangrove forests. We find that (1) along-shelf changes in TA and DIC exhibit strong linear relationships that are consistent with basin-scale net calcium carbonate precipitation; (2) ecosystem-driven changes in TA and DIC are larger than offshore variations in $>70 \%$ of sampled seagrass meadows and mangrove forests, changes which are influenced by a combination of longer water residence times and community metabolic rates; and (3) the sampled mangrove forests show strong and consistent contributions from both organic respiration and other sedimentary processes (carbonate dissolution and secondary redox processes), while seagrass meadows display more variability in the relative contributions of photosynthesis and other sedimentary processes (carbonate precipitation and oxidative processes). The results of this study highlight the importance of resolving the influences of water residence times, mixing and upstream habitats on mediating the carbonate system and coastal air-sea carbon dioxide fluxes over coastal habitats in the Red Sea.
\end{abstract}

\section{Introduction}

Coral reefs, seagrass meadows and mangrove forests are sites of intense metabolic processes. These habitats are distributed heterogeneously in the coastal zone, at shallow depths where perturbations in the carbonate system by metabolic processes can have the greatest influence on water chemistry and airsea carbon dioxide $\left(\mathrm{CO}_{2}\right)$ exchange (Bauer et al., 2013; Camp et al., 2016; Cyronak et al., 2018; Gattuso et al., 1998; Guannel et al., 2016; Unsworth et al., 2012).

The cumulative impact of coastal habitats on the carbonate system, along with their overall importance in the global carbon cycle, is difficult to quantify and is poorly represented when compared to knowledge of open-ocean processes (IPCC, 2014). The open ocean is geographically separated from the benthos and land so their respective influences on the carbonate system can often be ignored over short timescales. In addition to the influence of metabolism in coastal habitats, the carbonate system of the coastal zone is also influenced by both the benthos and land over short timescales. Thus, terrestrial and freshwater inputs (dissolved and particulate), sediment exchanges, biological processes, and changes in circulation and water residence time must all be considered when studying perturbations in the carbonate system of the coastal zone (Doney, 2010; Duarte et al., 2013; Giraud et al., 2008; Jiang et al., 2014; IPCC, 2014).

Changes in carbonate system concentrations in the coastal zone can be conservative or non-conservative (Jiang et al., 2014). Conservative changes arise from the mixing of water masses and from evaporation. The salinity of a water mass is a conservative property and can be used to estimate the 
conservative component of changes in carbonate system concentrations. The conservative mixing of coastal water masses is often conceptualised as a two-end-member problem, with changes in carbonate system concentrations linearly related to salinity between a freshwater end-member (e.g. rivers, land run-off) and an offshore oceanic end-member (Jiang et al., 2014; Robbins, 2001). Non-conservative changes in the coastal zone are driven by metabolic processes, sediment exchanges and land inputs (Duarte et al., 2013; Jiang et al., 2014). As such, these non-conservative changes can be measured as anomalies in the carbonate system relative to conservative mixing.

The lack of significant freshwater inputs, via rivers and rainfall, in the arid Red Sea means that offshore waters are the only source of mixing exchange to the coastal zone, allowing for the implementation of a single-end-member mixing model (Sofianos and Johns, 2003). A constant oceanic salinity for the offshore region cannot be used to model conservative behaviour, due to basin-scale evaporation which causes a south-north increase in salinity along the central axis of the Red Sea. The observed south-north increase in alkalinity is smaller than conservative behaviour predicts, due to chemogenic and biogenic calcium carbonate $\left(\mathrm{CaCO}_{3}\right)$ precipitation throughout the Red Sea (Jiang et al., 2014; Steiner et al., 2014, 2018; Wurgaft et al., 2016). Thus, the linear relationships in offshore carbonate system concentrations, combined with the additional variability of coastal evaporation, define the expected conservative behaviour for the entire coastal zone of the Red Sea (Fig. 1).

Here we explore the carbonate system in the eastern (Saudi-EEZ) coastal zone of the Red Sea. We examine concentrations of total alkalinity (TA) and dissolved inorganic carbon (DIC) over and around coral reefs, seagrass meadows and mangrove forests, and we compare these to the same properties measured in offshore Red Sea surface waters. By using a simple single-end-member mixing model, which accounts for conservative changes in the carbonate system of the coastal zone, we detect large ecosystem-driven anomalies in coastal habitats. Smaller non-conservative changes, particularly characteristic of coral reefs, were not able to be detected with high confidence using the oversimplified circulation model but could be resolved with more knowledge of offshore circulation and variability of the carbonate system in the Red Sea.

\section{Methods}

\subsection{KAUST observations}

Between February 2016 and August 2017, seawater samples were collected in the Red Sea during daylight hours from six oceanographic cruises (January-February 2016, JanuaryFebruary 2017, March 2017, April 2017, May 2017, JulyAugust 2017) and at coastal time series stations (Fig. 2, Ta- ble S1 in the Supplement). The six oceanographic cruises visited three types of shallow coastal habitats, spanning the full length of the Saudi-EEZ coast. Open-water samples were also collected on cruises $>50 \mathrm{~m}$ upstream from shallow coastal habitats. The coastal time series sampling of surface waters was conducted every 2 weeks at four stations near the King Abdullah University of Science and Technology (KAUST): a transition water station $\left(22.3093^{\circ} \mathrm{N}, 38.9974^{\circ} \mathrm{E}, n=31\right)$, a coral reef station $\left(22.25285^{\circ} \mathrm{N}, 38.96122^{\circ} \mathrm{E}, n=32\right)$, a mangrove forest station $\left(22.3394^{\circ} \mathrm{N}, 39.0885^{\circ} \mathrm{E}, n=23\right)$ and a seagrass meadow station $\left(22.3898^{\circ} \mathrm{N}, 39.1355^{\circ} \mathrm{E}, n=32\right)$ (Fig. S1).

Transition and offshore water samples were collected using a Niskin bottle deployed off the side of the vessel, together with temperature $(T)$ and salinity $(S)$ recorded with an Ocean Seven 305Plus multi-parameter conductivitytemperature-depth (CTD) instrument. Seawater samples from coastal habitats were collected at a depth $>30 \mathrm{~cm}$ below the surface and in close proximity to the habitat. They were collected with a $10 \mathrm{~cm}$ diameter by $30 \mathrm{~cm}$ long polyvinyl chloride cylinder, to avoid disturbing the benthic organisms and the associated resuspension of sediments or epiphytes. The cylinder was carefully moved over the ecosystem and sealed with rubber caps. Measurements of $S$ and $T$ were made at the sampling point using a hand-lowered Ocean Seven 305Plus multi-parameter CTD instrument. The cylinders were then transported to the vessel where water was carefully siphoned using a silicone tube.

Water samples were collected into $12 \mathrm{~mL}$ glass vials (DIC) and $50 \mathrm{~mL}$ plastic falcon tubes (TA), for all cruises except one (Cruise $\mathrm{ID}=\mathrm{CSM} 16)$ during which TA samples were collected in $12 \mathrm{~mL}$ glass vials. To halt biological activity, DIC and TA samples were poisoned to a concentration of $0.02 \%$ mercuric chloride solution. TA and DIC were measured at KAUST according to the standard operating procedures set out by Dickson et al. (2007). DIC was measured by an infrared technique with an Apollo SciTech ASC3 DIC analyser, and TA was measured by open-cell titration with $0.1 \mathrm{M}$ hydrochloric acid using a Mettler Toledo T50 autotitrator equipped with an InMotion Pro Autosampler using non-linear curve fitting to determine an equivalence point. Both measurements were standardised using Certified Reference Materials (CRM) obtained from Andrew Dickson (Scripps Institute of Oceanography). Observations were flagged based on the standard error between replicates, and those that had only single replicates or high standard error $\left(\mathrm{SE}>20 \mu \mathrm{mol} \mathrm{kg}{ }^{-1}\right)$ were excluded from further analysis $(n=17)$.

\subsection{WHOI observations}

Two oceanographic cruises led by the Woods Hole Oceanographic Institution (WHOI) were conducted in March 2010 and September-October 2011. Targeting open waters of the Red Sea, the cruises traversed the length of the Saudi-EEZ 
(a)

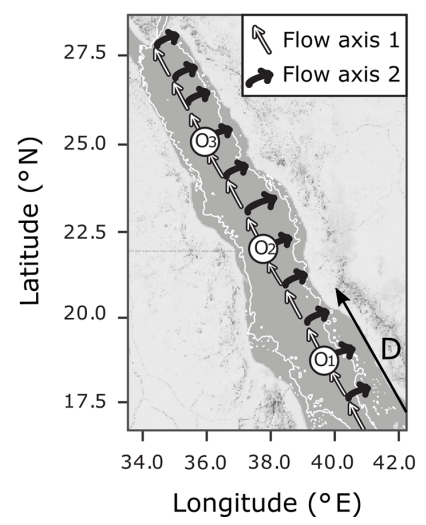

(b)

Step 1

Offshore model
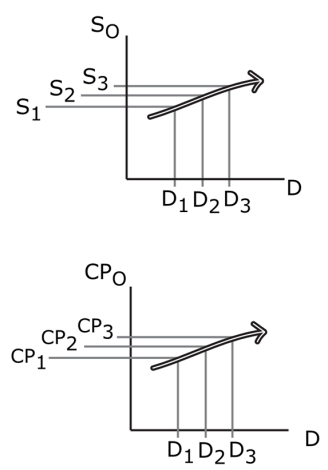

Step 2

Conservative changes

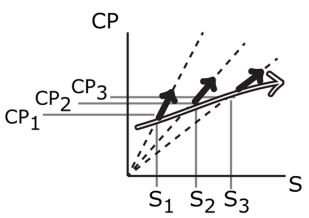

$\Longrightarrow$ Basin-scale trend

$\rightarrow$ Evaporation trend

along flow

Figure 1. Schematic of the single-end-member mixing model used in the present study. Panel (a) displays the assumed circulation pattern which has two flow axes overlaid on a map of the Red Sea produced using @Stamen Design LLC and R software. Flow axis 1 is along the south-north central axis where waters experience cumulative changes due to basin-scale evaporation and calcification. Flow axis 2 is perpendicular to this axis, where it is assumed that evaporative effects prevail as waters transition from offshore locations $\left(O_{i}\right)$ to coastal regions. The thin white line indicates the $200 \mathrm{~m}$ bathymetry. Panel (b) explains the single-end-member mixing model in two steps, to determine conservative estimates of a carbonate parameter (CP:TA or DIC) for the coastal zone. $O_{i}$ represents an offshore end-member at a location in offshore waters lying along flow axis 1 (the central axis) at distance $D_{i}$, from a fixed reference point in the southern Red Sea, and corresponding salinity $S_{i}$ and carbonate parameter measurement $\mathrm{CP}_{i}$, as derived from basin-scale linear relationships. $\mathrm{CP}_{i}$ is then scaled along the simple dilution and concentration (SDC) line to obtain coastal estimates for carbonate parameters.

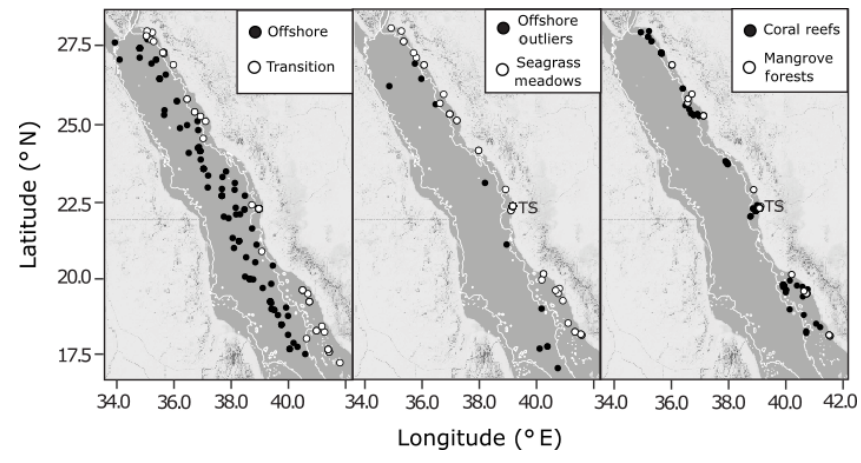

Figure 2. The spatial distribution of combined observations from the Red Sea datasets used in the present study, shown against a $200 \mathrm{~m}$ bathymetry boundary (thin white line) overlaid on maps of the Red Sea produced using (CStamen Design LLC and R Software. Observations are classified as offshore, transition, seagrass meadows, coral reefs or mangrove forests. Time series stations are indicated as TS (Fig. S1). Outliers identified in offshore observations are also shown.

coast. $T$ and $S$ observations were acquired using the ship's CTD, and water samples were collected using Niskin bottles on the CTD rosette. On deck, water samples were transferred into $250 \mathrm{~mL}$ glass bottles using a length of silicone tubing, taking care to minimise exchange with the atmosphere, and the samples were poisoned with $50 \mu \mathrm{L}$ of a saturated mercuric chloride solution immediately after acquisition. The samples were analysed at WHOI for TA and DIC using a Marianda VINDTA 3C analysis system. TA was determined by non-linear curve fitting of data obtained by open-cell titrations, and DIC concentrations were determined by coulometric analysis, according to the standard operating procedures set out by Dickson et al. (2007). Both measurements were standardised using CRM obtained from Andrew Dickson. The difference between replicate samples averaged 0.6 and $1.5 \mu \mathrm{mol} \mathrm{kg}^{-1}$ for alkalinity and 3.0 and $2.7 \mu \mathrm{mol} \mathrm{kg}^{-1}$ for DIC, for the 2010 and 2011 cruises respectively.

\subsection{Published datasets}

Open-water surface observations $(<50 \mathrm{~m})$ collected over 2007-2010 were sourced from published datasets (Table S1; Hydes et al., 2012; Picheral et al., 2014; Steiner et al., 2018). Data were constrained to a comparable area of the Red Sea in which new observations collected by KAUST and WHOI were obtained $\left(17-28^{\circ} \mathrm{N}, 30-44^{\circ} \mathrm{E}\right)$. A recent study by Steiner et al. (2018) detected differences between new Red Sea TA observations obtained in 2015, 2016, and 2018 and old Red Sea TA observations from a 1998 cruise on the RV Sea Surveyor (Steiner et al., 2014). We reassess these differences between old and new Red Sea data comparing the new data from Steiner et al. (2018) and from this study with old data collected aboard the RV Sea Surveyor (Steiner et al., 2014) and the RV Marion Dufresne (Papaud and Poisson, 1986). Consequently, we elected to only use data collected within a decade of coastal observations (2007-2017) for our study, as long-term changes were observed in carbonate parameters (Fig. 3). 


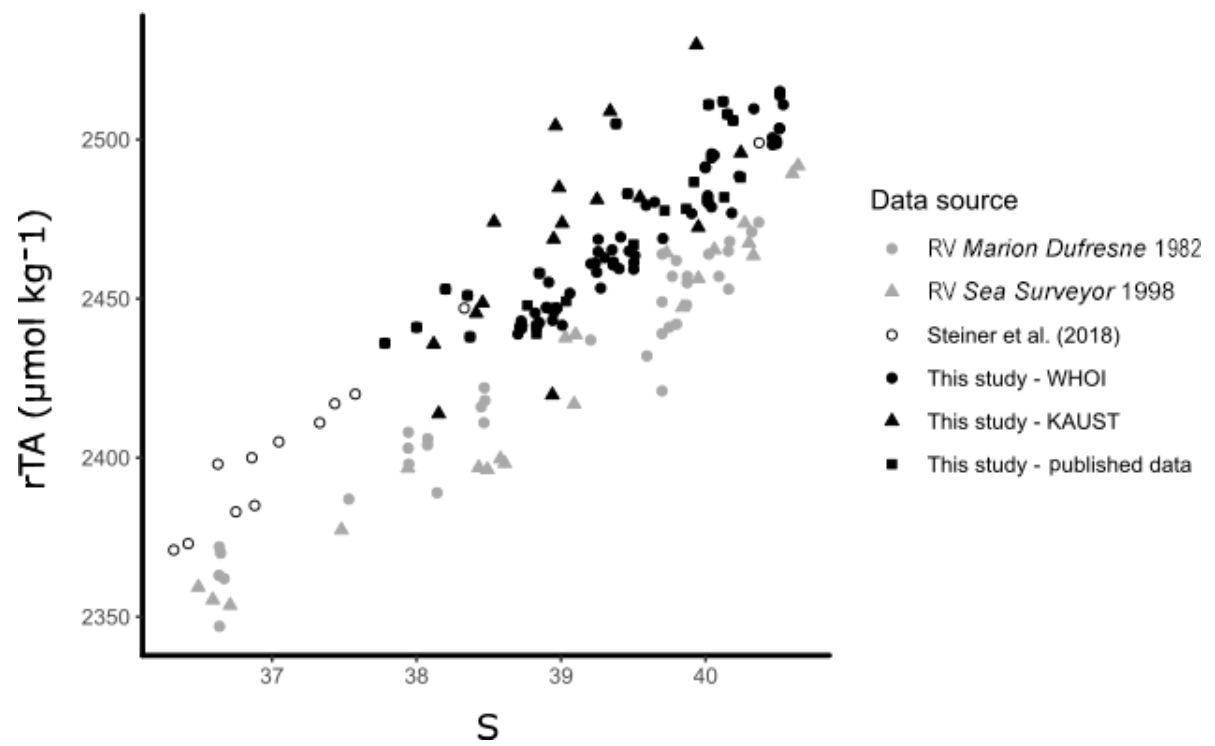

Figure 3. Offshore observations of TA are shown against $S$, as in Steiner et al. (2018), to illustrate the difference between old (grey) and new (black) observations of carbonate chemistry in the offshore surface waters of the Red Sea. The observations presented from this study are only from offshore waters (excluding outliers).

\subsection{Definition of the coastal zone}

The stations used to define the offshore end-member were those (from KAUST, WHOI and published sources) with bottom depths $>200 \mathrm{~m}$ according to the General Bathymetry Chart of the Oceans (GEBCO) gridded bathymetry with a 30 arcsec resolution (GEBCO_2014 Grid, version 20150318, https://www.gebco.net, last access: 3 September 2019). All other open-water observations (i.e. stations with bottom depths $<200 \mathrm{~m}$ and not collected over a coastal habitat) were labelled as coastal transition waters. Samples collected over a coastal habitat were classified by the corresponding habitat: coral reef, seagrass meadow or mangrove forest.

\subsection{Implementing a single-end-member mixing model}

A single-end-member mixing model was used to model conservative TA (cTA) and conservative DIC (cDIC) for coastal observations. First, the distance of a point along the central axis of the Red Sea in kilometres $(D)$ was calculated for each observation. This was done using the "alongTrackDistance" function (default settings) in the R package "geosphere" (Hijmans, 2017) with the reference point $12.7737^{\circ} \mathrm{N}, 43.2618^{\circ} \mathrm{E}$ to represent $D=0$ and the reference point $28.2827^{\circ} \mathrm{N}$, $34.0694^{\circ} \mathrm{E}$ to define the position of the central south-north axis. The single-end-member model was then implemented by (1) describing the linear variations in offshore $S$, TA and DIC with $D$, so that predictions of offshore $S\left(S_{\mathrm{O}}\right)$, offshore $\mathrm{TA}\left(\mathrm{TA}_{\mathrm{O}}\right)$ and offshore DIC ( $\left.\mathrm{DIC}_{\mathrm{O}}\right)$ can be made from the value of $D$ corresponding to coastal observations, and then (2) calculating cTA and cDIC for observations according to Eqs. (1)-(2), which predict the simple dilution and concen- tration (SDC) effects of evaporation (Fig. 1).

$$
\begin{aligned}
& \mathrm{cTA}=\left(S / S_{\mathrm{O}}\right) \cdot \mathrm{TA}_{\mathrm{O}} \\
& \mathrm{cDIC}=\left(S / S_{\mathrm{O}}\right) \cdot \mathrm{DIC}_{\mathrm{O}}
\end{aligned}
$$

Here $S$ is the observed salinity at a coastal observation point, and $S_{\mathrm{O}}, \mathrm{TA}_{\mathrm{O}}$ and $\mathrm{DIC}_{\mathrm{O}}$ are calculated from the linear relationships found in step 1 , for a distance $D$ corresponding to the observation point.

Other carbonate parameters, the partial pressure of $\mathrm{CO}_{2}$ $\left(p \mathrm{CO}_{2}\right), \mathrm{pH}$ and the saturation state of aragonite $\left(\Omega_{\mathrm{Ar}}\right)$, were calculated with the "carb" function from the R package "seacarb" (Gattuso et al., 2018), which estimates the seawater carbonate system in the absence of borate and sulfate. We employed this function assuming silicate and phosphate concentrations of zero, using $K_{1}$ and $K_{2}$ constants from Millero (2010), and using the total scale for $\mathrm{pH}$. Both conservative mixing values and observed values were calculated for other carbonate parameters, from cTA and cDIC, and observed TA and DIC.

Residual TA (rTA) and residual DIC (rDIC) were then calculated by subtracting cTA and cDIC from observed TA and observed DIC respectively. Residuals of the other carbonate parameters $\left(\mathrm{r} p \mathrm{CO}_{2}, \mathrm{rpH}, \mathrm{r} \Omega_{\mathrm{Ar}}\right)$ were calculated by subtracting conservative values of other carbonate parameters (calculated from cTA and (DIC) from observed values of other carbonate parameters (calculated from TA and DIC observations).

\subsection{Model assumptions and limitations}

The single-end-member mixing model assumes simple twodimensional circulation in a region that exhibits more com- 
plex flow. The modelled flow follows a south-north trajectory along the central axis of the Red Sea, with perpendicular coastal flushing from offshore waters located at similar distances along the central axis (Fig. 1). This allows changes in the carbonate chemistry of offshore waters, due to both conservative and non-conservative processes, and conservative coastal evaporation to be modelled.

This is a substantial simplification - in fact, the Red Sea has a complex surface flow displaying multiple dynamic eddies along its length (Sofianos and Johns, 2003; Zhan et al., 2014). Depending on the direction of flow, these eddies promote coastal flushing from offshore waters originating further north or further south along the central axis of the Red Sea, mixing in a way the simple single-end-member mixing model cannot capture. Other limitations of the simple singleend-member mixing model include its inability to account for coastal upwelling along the continental shelf, variable mixing of Gulf of Aden waters with Red Sea offshore waters, and changes in basin-scale evaporation and calcification which have been documented in previous studies (Anderson and Dyrssen, 1994; Churchill et al., 2014; Krumgalz et al., 1990; Papaud and Poisson, 1986; Steiner et al., 2018).

These limitations cannot be addressed within the present study and would require a sustained observational effort to address knowledge gaps in the carbonate chemistry of the Red Sea, combined with more complex circulation models. Complex circulation models could capture some largescale variance in circulation, but they are costly simulations that may still produce questionable results due to the unresolved coastal bathymetry of the Red Sea. Instead, we use the $99 \%$ prediction interval (PI) of offshore carbonate chemistry residuals as a bound of model error and to capture deviations from modelled carbonate chemistry due to the pre-described variations in mixing.

\subsection{Statistical tests}

All statistical tests were performed using R software v3.4.3 (R Core Team, 2018) with a $95 \%$ confidence level. Leastsquares regression analysis was used on a spatial data subset (all observations excluding time series) to calculate linear relationships with $D$ for $S, T$ and carbonate parameters, thus determining how $S, T$ and carbonate parameters vary along the central axis from south to north. Least-squares regression analysis was also used to calculate relationships between rTA and rDIC. The square of Pearson's correlation coefficient $\left(r^{2}\right)$ was used to evaluate the strength of the linear relationships. Least-squares analysis of variance (LS-ANOVA) was used to investigate interaction effects between $D$ and habitat groups to test for significant differences between linear regression slopes with $D$ across habitats for $S, T$ and carbonate parameters.

Seagrass meadows and mangrove forests displayed greater variances compared to other groups (maximum variance / minimum variance $>2$ ) between carbonate parame- ters, violating the assumption of homoscedasticity between groups required for parametric analysis of variance. For this reason, a Wilcox's robust ANOVA (WR-ANOVA) was chosen to account for heteroscedasticity across habitat groups. WR-ANOVAs for differences in medians were conducted between observations from offshore waters, transition waters and coastal habitats. Tests between medians were chosen, rather than between means, as mangrove habitats displayed skewed TA and DIC observations. Wilcox's robust statistical methods were implemented using the R package "WRS2" (Mair and Wilcox, 2018), with the functions "med1way" for testing differences in medians and a bootstrapped $t$ test employed ( $\mathrm{R}$ Code in the Supplement) for post hoc analysis.

To assess the strength of seasonal cycles at time series stations and to test differences between habitats, a seasonal proxy (SP) was constructed from $T$ observations at the transition and coral reef time series stations. A cubic smoothing spline, with a smoothing parameter of 0.55 , was fit to three iterations of the $T$ seasonal cycle at the stations (Forsythe et al., 1977). The fit was then scaled such that a value of 1 indicates peak summer period, and a value of -1 indicates peak winter period. Parametric tests were chosen to detect correlations with season, as variances across season were roughly homoscedastic. LS-ANOVA was used to assess the significance of seasonal cycle as a predictor in time series observations, to infer the presence of interaction effects between habitats and season in time series observations, and to infer differences in rTA : rDIC slopes between time series observations and spatial observations. WR-ANOVA was also performed on time series observations to assess median differences between the four time series stations.

\section{Results}

\subsection{The Red Sea offshore end-member}

The offshore carbonate system of the Red Sea was characterised along the south-north central axis. Offshore waters exhibited significant and strong (high $r^{2}$ ) linear increases in $S$, TA and DIC along the central south-north axis of the Red Sea as indicated by respective regression analysis with $D$ (Fig. 4, Table S3). TA and DIC were normalised to a $S$ of 35 (nTA and nDIC), and both exhibited significant and weak (low $r^{2}$ ) linear decreases along the central south-north axis of the Red Sea (Fig. 5). However, winter nDIC values appear to deviate from this linear relationship. The nTA and nDIC co-varied along this axis in an average ratio of $0.69\left(\mathrm{SE}=0.06, r^{2}=0.60, F=147.7, p<0.001\right) \mathrm{nTA}$ to $1 \mathrm{nDIC}$ (Fig. 5c). A significant and weak (low $r^{2}$ ) linear decrease was found for $T$ against $D$, which displayed clear seasonal dependencies between summer and winter-spring $T$ (Fig. 4). A significant and weak (low $r^{2}$ ) increase in $\mathrm{pH}$, a significant and weak (low $r^{2}$ ) decrease in $p \mathrm{CO}_{2}$, and no 
significant linear relationship in $\Omega_{\mathrm{Ar}}$ against $D$ were also observed.

In defining the offshore end-member for implementation in the single-end-member mixing model, offshore observations not representative of the expected linear relationships in the surface offshore Red Sea were removed. These were identified as 11 outlying offshore observations exhibiting a Cook's distance greater than 5 times the mean in at least one of the three linear models of $D$ against $S$, TA and DIC (Fig. 1; Cook and Weisberg, 1997). Linear models were then re-fit with the remaining offshore observations $(n=104)$ to yield Eqs. (3)-(5), to be substituted into Eqs. (1)-(2) to complete the single-end-member mixing model (Fig. 1).

$S_{\mathrm{O}}=0.00157 \cdot D+37.47$

$\mathrm{TA}_{\mathrm{O}}=0.0510 \cdot D+2407$

$\mathrm{DIC}_{\mathrm{O}}=0.0437 \cdot D+2029$

To approximate the error of the single-end-member mixing model, $99 \%$ prediction intervals $(99 \%$ $\mathrm{PI}=$ mean $\pm 2.576 \cdot \mathrm{SD}$ ) were calculated by applying the single-end-member mixing model to offshore observations to yield rTA, rDIC, $\mathrm{r} p \mathrm{CO}_{2}, \mathrm{rpH}$ and $\mathrm{r} \Omega_{\mathrm{Ar}}$ (Table S2). These $99 \%$ PIs represent a cumulative error due to the natural variations in $S_{\mathrm{O}}, \mathrm{TA}_{\mathrm{O}}$ and $\mathrm{DIC}_{\mathrm{O}}$, along with the error propagation associated with the calculations of other carbonate parameters. Two offshore observations used in defining the offshore end-member fell outside the $99 \%$ PI, both exhibiting high TA and one exhibiting high DIC.

\subsection{The Red Sea coastal zone}

Coastal observations also displayed significant linear relationships with $S$ from the southern to northern Red Sea (Fig. 4). At the transition and coral reef sites, increases in $S$ with $D$ were significant and of comparable strength (indicated by $r^{2}$ values) to those observed offshore, while a weaker (lower $r^{2}$ ) increase in $S$ with $D$ was observed at seagrass meadows (Table S3). No significant increase in $S$ with $D$ was observed at mangrove forests. No interaction effects between habitat type and $D$ were observed for $S$. This means that rates of increases in $S$ with $D$ did not differ significantly between habitats or offshore waters (excluding mangrove forests; $F=1.55, p=0.203$ ). Along with the results of Fig. 6a, it can consequently be concluded that, irrespective of $D$, compared to offshore waters significantly higher median $S$ values were observed at mangrove forests across the Red Sea coastal zone. Similarly, it can be concluded that irrespective of $D$ median $S$ for transition waters, coral reefs and seagrass meadows were comparable to the median $S$ observed offshore.

Within coral reefs, seagrass meadows and mangrove forests, decreases in $T$ with $D$ were significant and stronger (higher $r^{2}$ ), compared to the decreases observed in offshore waters (Fig. 4, Table S4). Tests for interaction effects indicated that rates of change of $T$ with $D$ differed significantly among habitats $(F=7.54, p<0.001)$, but these differences were small and did not deviate largely away from those observed in offshore waters (Fig. 4). Transition waters displayed similar $T$ to offshore waters along the entire length of the Red Sea. Differently, the three coastal habitats displayed on average slightly higher average $T$ in the southern Red Sea, compared to offshore waters (Fig. 4). There was a high sampling bias towards winter-spring in coastal observations, and corresponding measurements of in situ $T$ were not successfully made for all summer observations. Consequently, the seasonal dependencies cannot be confidently compared or described here.

Compared to offshore waters, TA across transition, coral reef and seagrass meadow sites displayed similar rates of increases with $D$ but differing median values and distribution (Figs. 4, 6a). Increases in TA with $D$ for each coastal habitat were weaker (lower $r^{2}$ ) compared to those observed in offshore waters, with significant linear relationships present for all habitats but mangrove forests. There were no interaction effects between $D$ and habitat groups (excluding mangrove forests; $F=0.95, p=0.417$ ). This means that TA at coastal sites displayed similar rates of increase with $D$ compared to offshore waters. Consequently, when also considering results presented in Fig. 6a, it can be concluded that transition waters, coral reefs and mangrove forests displayed comparable median TA to offshore waters. Additionally, compared to offshore waters, lower median TA was observed at seagrass meadows across the Red Sea coastal zone (Figs. 4, 6a). TA sampled in transition waters and all coastal habitats exhibited a higher variability compared to that measured offshore.

Increases in DIC with $D$ were also weaker (lower $r^{2}$ ) for coastal observations compared to offshore waters, with significant linear relationships observed only for transition and coral reef waters. An interaction effect with $D$ across habitat was observed (excluding mangrove forest and seagrass meadow; $F=4.66, p=0.011$ ). The significance of this interaction effect was driven by coral reef waters on average displaying lower DIC in the southern Red Sea compared to offshore waters and comparable DIC in the northern Red Sea (Fig. S4a). The variability of coral reef waters was much higher compared to offshore and transition waters. Compared to offshore waters, transition waters showed small increases in median DIC, seagrass meadows showed comparable median DIC and higher variability, and mangrove forests displayed higher median DIC with higher variability around this median (Fig. 6a).

Observations of $\mathrm{pH}$ and $p \mathrm{CO}_{2}$ showed statistically significant, but relatively weak (low $r^{2}$ ), linear relationships with $D$ for only seagrass meadow and coral reef sites (Figs. 4, 6a). No interaction effects were observed between these habitats and offshore waters. This means that rates of change with $D$ were statistically similar (excluding transition water and mangrove forest; $F=1.54,1.98, p=0.217,0.141$ for $\mathrm{pH}$ and $p \mathrm{CO}_{2}$ ). Compared with offshore waters, $\mathrm{pH}$ and $p \mathrm{CO}_{2}$ at coral reefs showed statistically similar medians and greater 


\section{Offshore}
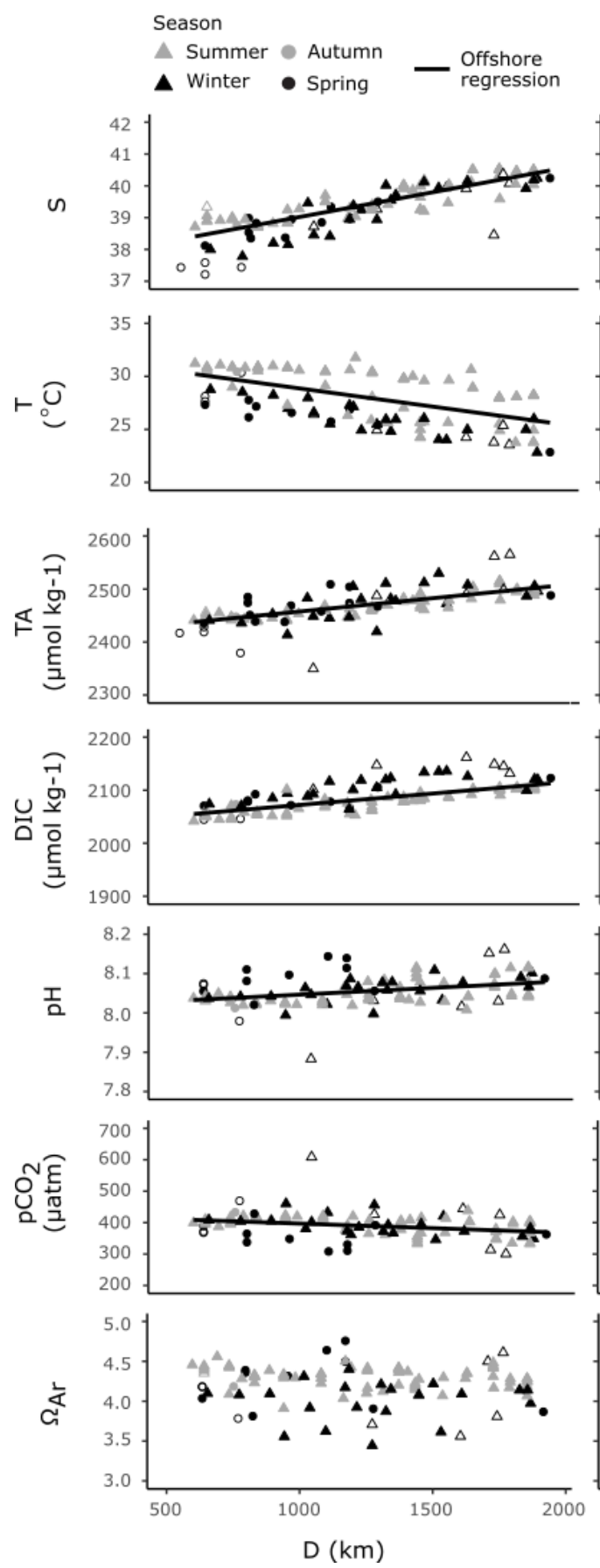

\section{Coastal}
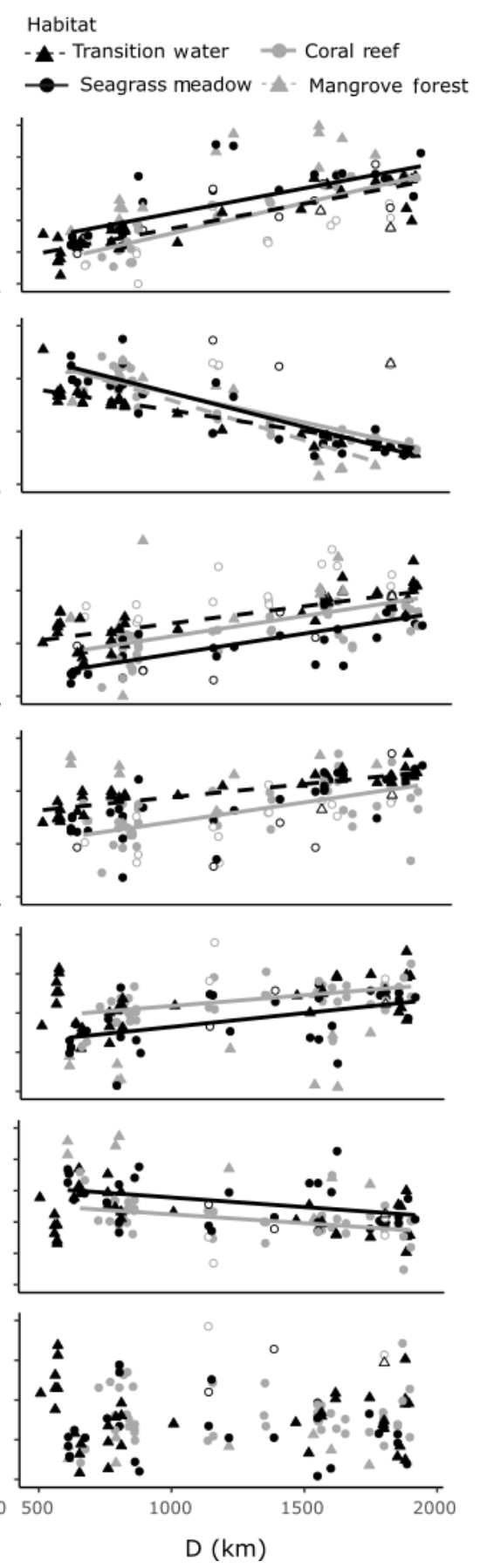

Figure 4. Offshore observations of $S, T$ and carbonate parameters (left) and four coastal habitats (right) are presented against distance along the south-north central axis $(D)$, on the same scales. Significant linear regressions for all combinations of variables are drawn as lines, with associated statistics reported in Table S3. Offshore outliers were not included in determining offshore regressions against $D$. Coastal observations from time series stations and an outlying mangrove observation were not included in regressions against $D$. Note that not all coastal observations are displayed, and an expanded scale is shown in Fig. 6. Hollow symbols indicate offshore outliers (right panels) and coastal summer observations (left panels). 
variability. Compared to offshore waters, mangrove forest and seagrass habitats displayed lower median $\mathrm{pH}$, higher median $p \mathrm{CO}_{2}$ and greater variability. Compared to offshore waters, transition observations displayed slightly lower median $\mathrm{pH}$, higher median $p \mathrm{CO}_{2}$ and greater variability. As seen in offshore waters no significant linear relationships with $D$ were observed for $\Omega_{\mathrm{Ar}}$ at coastal habitats or transition waters; however coastal observations of $\Omega_{\text {Ar }}$ displayed lower medians and higher variability, compared to offshore waters. Mangrove forests displayed the most variability in observed values across all carbonate parameters.

One outlying mangrove forest observation taken near KAUST in 2016 showed high TA values, and low DIC, leading to unrealistic estimations of other carbonate parameters (Fig. S2). Further, an isolated mangrove stand was sampled from an inland lake that was tidally flushed (Fig. S3a). The two observations taken from this mangrove stand contained much higher TA and DIC compared to observations from coastally residing mangrove stands. The outlying observation was excluded from analysis; however the observations from the inland mangrove stands were not.

\subsection{Coastal ecosystem anomalies}

Using a simple single-end-member mixing model, large nonconservative carbonate system residuals were detected in the coastal Red Sea (Fig. 6b). Slopes from least-squares linear regressions with $D$ indicate that non-conservative carbonate system residuals display no significant linear relationships along the south-north central axis of the Red Sea (Table S3, Fig. S5). Compared to the $99 \%$ PI, coral reefs exhibited lower median rDIC and lower median rTA, whilst transition waters exhibited similar median rTA and higher median rDIC, although differences were the smallest at these sites. Changes at seagrass meadows and mangrove forests were more pronounced, with a relatively larger variability. Compared to the $99 \%$ PI, both habitats displayed lower median rTA; however lower median rDIC was observed at seagrass meadows whilst higher median rDIC was observed at mangrove forests.

Non-conservative carbonate system residuals that fall outside of the $99 \%$ PI deviate significantly from the expected conservative behaviour of the coastal zone and are concluded to be ecosystem-driven anomalies in the carbonate system (Fig. 6b). Transition waters displayed the lowest occurrences of ecosystem-driven anomalies, equally distributed towards higher rTA and lower rTA compared to the $99 \%$ PI and mostly towards higher rDIC compared to the $99 \%$ PI. Coral reefs also displayed a relatively low range of rTA and rDIC ecosystem-driven anomalies, equally distributed to higher and lower values for rTA compared to the $99 \%$ PI and mostly towards lower rDIC compared to the $99 \%$ PI. Seagrass meadows and mangrove forests displayed markedly higher occurrences of ecosystem-driven anomalies compared to transition waters and coral reefs. Sea- grass meadows displayed ecosystem-driven anomalies distributed mostly towards lower rTA compared to the $99 \%$ PI and rDIC ecosystem-driven anomalies distributed mostly towards lower rDIC values compared to the $99 \%$ PI. Mangrove forests displayed ecosystem-driven anomalies distributed mostly towards lower rTA compared to the $99 \%$ PI and ecosystem-driven anomalies distributed mostly towards higher rDIC compared to the $99 \%$ PI.

Coastal observations of other carbonate parameters displayed lower median $\mathrm{rpH}$, higher median $\mathrm{r} p \mathrm{CO}_{2}$ and lower $\mathrm{r} \Omega_{\mathrm{Ar}}$ compared to the $99 \%$ PI. Differences in other carbonate parameters compared to the $99 \%$ PI were most pronounced and displayed a large variability in mangrove forests. A significant proportion of ecosystem-driven anomalies in other carbonate parameters was detected at all coastal habitat types. In transition waters, mangrove forests and seagrass meadows, these ecosystem-driven anomalies were mostly observed to have lower $\mathrm{pH}$, higher $p \mathrm{CO}_{2}$ and lower $\Omega_{\mathrm{Ar}}$ compared to the $99 \%$ PI. Compared to the $99 \%$ PI, coral reefs exhibited a relatively equal distribution of both high and low ecosystem-driven anomalies in $\mathrm{pH}$, a small number of high ecosystem-driven anomalies in $p \mathrm{CO}_{2}$ and low ecosystem-driven anomalies in $\Omega_{\mathrm{Ar}}$.

\subsection{Coastal time series}

Despite their proximity, there were significant differences in $T$ and $S$ between the three coastal time series sites (Fig. 7, Table S6). The coral reef and transition stations displayed similar $S$ of comparable variability, exhibiting no variation with season. Observations of $S$ at the seagrass meadow station were higher and more variable than those observed at coral reef and transition stations. A seasonal dependency in $S$ was indicated by correlation with the seasonal proxy at this station; however, the correlation is weak and the cycle exhibits a small amplitude. The mangrove forest displayed the highest $S$, exhibiting no relationship with season and higher variability compared to the coral reef and transition stations.

Strong seasonal dependencies in $T$ were observed at all four time series stations. The seasonal cycles exhibited slower rates of decreases in $T$ towards winter and larger rates of increase in $T$ towards summer. The interaction effect between habitat and the seasonal proxy was significant, indicating that seasonal cycles of $T$ changed between habitat $(F=3.99, p=0.01)$. Compared to the transition and coral reef stations, the $T$ observed at the seagrass stations was often higher in winter and lower in summer, whilst $T$ observed at the mangrove forest station was only higher in summer (Figs. 7, S4b).

The coral reef and transition stations displayed a similar series of observations of TA, DIC and their respective residuals. The seagrass meadow station was the only station at which strong, statistically significant seasonal cycles were observed in both TA and DIC. During summer, the TA and DIC were lower at the seagrass meadow station compared to 
the transition and coral reef stations, whereas similar TA and DIC were seen at all stations during winter. Similarly, during summer rDIC was lower at the seagrass meadow station compared to that observed at the transition and coral reef stations. In winter rTA and rDIC did not completely return to values observed at the transition and coral reef stations. Weak (low $r^{2}$ ), statistically significant seasonal cycles were observed at the seagrass station in $\mathrm{pH}$ and $p \mathrm{CO}_{2}$, and at the transition station in DIC, although no clear deviations from other stations exist in these carbonate parameters. Compared to the other three stations, the mangrove forest station displayed no correlations with the seasonal proxy for all carbonate parameters and exhibited much larger variations. TA and DIC at the mangrove forest station were similar to TA and DIC at transition and coral reef stations, indicated by differences in medians. However, rTA and rDIC at the mangrove forest station more closely resembled rTA and rDIC observed at the seagrass station than at the other two stations, as indicated by differences in medians. No large differences in medians were observed across other carbonate parameters and their respective residuals.

\subsection{Relationship between rTA and rDIC}

Slopes, intercepts and appropriate statistics are presented in Table 1 for linear regression analysis of transition waters, coral reefs, seagrass meadows and mangrove forests. The slope of the relationship between rTA and rDIC was similar between the time series observations and the spatial observations in transition waters, coral reefs and mangrove forests ( $F=1.05,1.11$ and 0.07 respectively; $p=0.309,0.295$ and 0.794 respectively) but different in seagrass meadows $(F=$ $6.44, p=0.014)$, as indicated by the significance of interaction effects between rDIC across observation subsets for each habitat.

Transition water and coral reef observations displayed a significant and weak (low $r^{2}$ ) linear relationship between rTA and rDIC with an intercept close to zero. Seagrass meadow observations collected from the time series station displayed a significant and strong (high $r^{2}$ ) linear relationship between rTA and rDIC, but the spatial subset of observations did not. At the seagrass meadow station there was a significant difference in slope of 0.36 and 0.73 between the spatial and time series subsets respectively, with both regressions displaying similar negative rTA intercepts. The two observations from the inland mangrove stand deviated largely from the extrapolated linear relationships calculated using coastal mangrove stands and as such were excluded from the following regression analysis. Mangrove forest observations displayed a significant and strong (high $r^{2}$ ) linear relationship between rTA and rDIC over both subsets of data, with a negative rTA intercept and a slope of 0.62 and 0.60 for spatial and time series observations respectively.

\section{Discussion}

The relatively simple oceanography of the offshore Red Sea, with only one oceanic water mass influencing a narrow basin, yields simple linear relationships in salinity $(S)$, temperature $(T)$, total alkalinity (TA), dissolved inorganic carbon (DIC), $\mathrm{pH}$ and $\mathrm{pCO}_{2}$ along the south-north central axis (Fig. 4). The observed increases in TA along the central axis of the Red Sea were smaller than would be conservatively predicted from the central axis $S$ data (Fig. 5). This is consistent with previous studies which found that basin-scale calcification produces non-conservative deficits of TA that accumulate along the south-north central axis (Jiang et al., 2014; Steiner et al., 2014, 2018; Wurgaft et al., 2016). The observed increases in DIC were also consistent with basin-scale calcification in summer-spring; however winter results showed more variability around this relationship. These linear relationships in offshore waters are reflected in the water chemistry of the coastal zone and are removed with the use of a single-end-member mixing model (Figs. 1; S5). Doing so enables us to study non-conservative perturbations of the carbonate system in shallow benthic habitats at the basin scale.

The single-end-member conservative mixing model estimates the conservative component of TA and DIC that is inherent from offshore waters. The variability, or error, of this conservative component is estimated from offshore observations by constructing a $99 \%$ PI for rTA and rDIC. This error bound reveals the extent to which habitats alter the carbonate system via ecosystem processes, whilst also testing the validity of our single-end-member mixing model. The $99 \%$ PI captures offshore variability in $S$, TA and DIC due to the effects of inter-annual differences, eddies and variable circulation patterns, which act along similar spatial scales in both the offshore and coastal zones.

We expected to observe only evaporation-driven increases in $S$ in the coastal zone, as freshening by land inputs and precipitation is not thought to be significant. Yet, roughly $25 \%$ of the $S$ observations in coral reefs and transition waters were lower than those observed in offshore waters, highlighting the simplifications inherent in the single-end-member mixing model (Figs. 4, 6a). In winter, this observed freshening could be due to winter precipitation, which is accounted for in the model. Alternatively, it could be due to effects that are not captured in the model, including seasonal rivers (wadis) caused by flash floods that occur mainly during OctoberMay (de Vries et al., 2013; Robbins, 2001). These flooding events have not been explored in the context of TA and DIC inputs. In summer, the observed freshening may be due to the influx of Gulf of Aden waters. This circulation pattern causes cross-shelf variations in surface $S$ along the coast, with salinities in coastal waters observed to be up to 2 units lower than corresponding offshore waters (Churchill et al., 2014; Sofianos and Johns, 2003; Wafar et al., 2016). The implications of this circulation pattern for the carbonate system have also not been characterised. This possibly obscures ecosystem- 


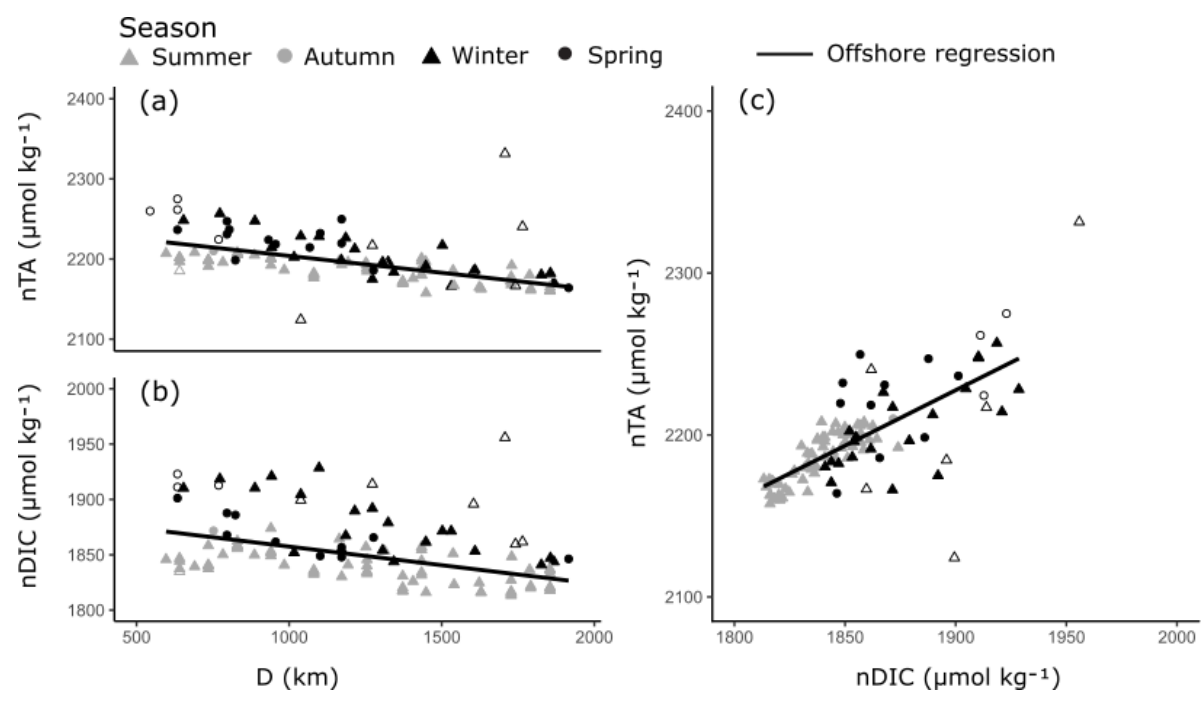

Figure 5. Linear relationships in nTA and nDIC along the south-north central axis of the Red Sea (a-b) and between nTA and nDIC (c) in the offshore waters. Symbols indicate the season in which samples were collected. All linear relationships were statistically significant and offshore outliers were not included in the linear regressions (hollow symbols).

driven perturbations of rTA and rDIC at coral reefs but has only a small effect on the large ecosystem-driven perturbations observed at mangrove forests and seagrass meadows.

By comparing relative changes in rTA and rDIC in each habitat, inferences can be made regarding the balance of ecosystem processes within Red Sea coastal habitats (Fig. 8, Albright et al., 2013; Challener et al., 2016; Cyronak et al., 2018; Gattuso et al., 1998; Zeebe and Wolf-Gladrow, 2001). If a habitat conforms closely to a linear relationship, it can be inferred that the balance of ecosystem processes is relatively uniform across sites. The slope of the linear relationship indicates the balance of ecosystem processes, with a value determined by the relative proportions of dominant ecosystem processes represented as directional vectors in Fig. 8a. Additionally, the intercepts of the linear relationship are inherited from the signals of upstream ecosystems, and the amplitude of an observation along this linear relationship is an indication of a combination of metabolic rate and residence time. It also follows that if a habitat does not conform closely to a linear relationship, then the balance of ecosystem processes is variable across sites. These inferences cannot be made with other carbonate parameters as, unlike TA and DIC, they are not invariant to changes in $T$ and pressure. Additionally, other carbon variables respond non-linearly to mixing and variations in TA and DIC. Particularly large but linked changes in TA and DIC with the ratio of roughly $1: 1$ cause other carbonate parameters to change very little (Zeebe and Wolf-Gladrow, 2001). This effect can be observed at the seagrass meadow time series station with the loss of seasonal cycle in other carbonate parameters (Fig. 7).

As our measurements are made from an open system, the impacts of air-sea $\mathrm{CO}_{2}$ gas exchange on DIC and the subsequent balance between rTA and rDIC cannot be completely discounted. Air-sea $\mathrm{CO}_{2}$ gas exchange may alter the rTArDIC relationship away from the balance of ecosystem processes towards negative rDIC. Offshore waters are a $p \mathrm{CO}_{2}$ source and further increases in $p \mathrm{CO}_{2}$ in seagrass meadows and mangrove forests will lead to further $\mathrm{CO}_{2}$ outgassing (Fig. 6b; Papaud and Poisson, 1986). However, this effect is relatively small compared to the contribution of ecosystem processes when large ecosystem anomalies are present in seagrass meadows and mangrove forests - a result of high, localised metabolic rates (Burkholz et al., 2019; Ho et al., 2014; Sea et al., 2018). Linked measurements of $\mathrm{CO}_{2}$ gas exchange with metabolic fluxes are required to resolve the magnitude of this effect for Red Sea coastal habitats.

All mangrove forests in the Red Sea are comprised of a single species, Avicennia marina (Almahasheer et al., 2016), and display a relatively uniform balance of ecosystem processes across the Red Sea (Fig. 8e). Both the time series data and the spatial data show statistically similar linear relationships (Fig. 8e, Table 1). It follows from this that differences in residence times and metabolic rates are the strongest driver of variability between sites, whilst underlying ecosystem processes remain relatively stable. The positive changes in rTA and rDIC are indicative of high respiration rates, mainly due to high rates of organic matter remineralisation, from sediments rich in organic carbon. This lowers $\mathrm{pH}$, inducing calcium carbonate dissolution, a mechanism which has been found to be important in previous process-based studies (Burdige and Zimmerman, 2002; Krumins et al., 2013; Meister, 2013; Middelburg et al., 1996). Changes in the negative direction, with deficits in rTA and rDIC, are less expected in mangrove forests, as sediments are rarely net autotrophic (Bouillon et al., 2008; Krumins et al., 2013; Zablocki et al., 2011), but could be inherited from upstream seagrass mead- 
(a)

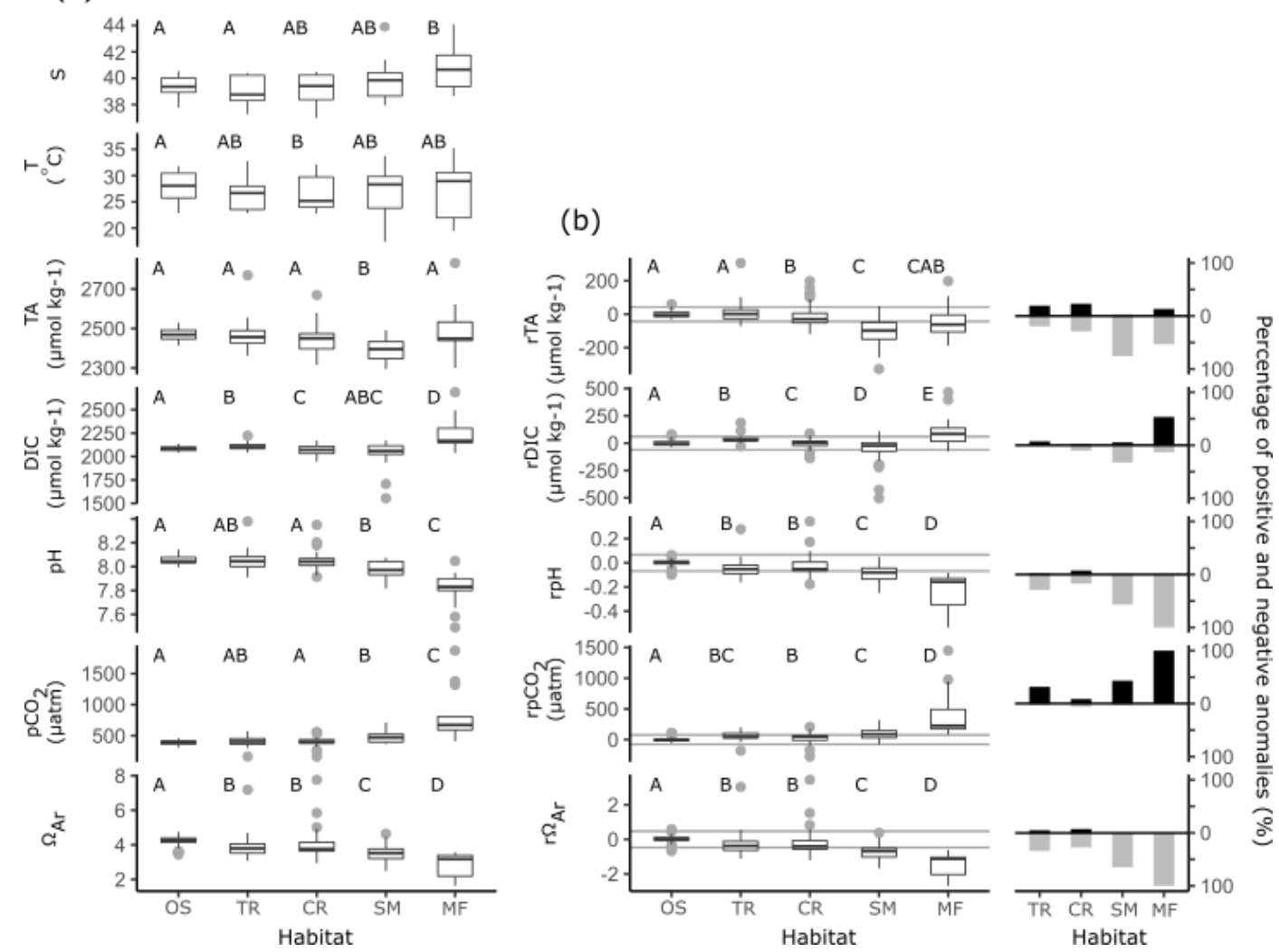

Figure 6. Box-plot distributions of (a) observed $S, T$, carbonate parameters and (b) non-conservative carbonate system residuals which are presented by the habitat group: offshore (OS), transition waters (TR), coral reef (CR), seagrass meadow (SM) and mangrove forest (MF). Each box plot displays the median, the first and third quartiles, and whiskers that extend to the mean \pm 1.5 times the inter-quartile range. Grey dots represent observations that extend outside the whiskers of the box plot. Grey lines in panel (b) indicate the upper and lower bounds of the $99 \%$ PI defined by offshore observations. The proportion of ecosystem anomalies (\%) observed in both the positive and negative directions are presented alongside and to the right of box plots in panel (b) (Table S4). Grouping letters (A-D) assigned above box plots indicate the results of post hoc bootstrapped $t$ tests, summarised from statistics presented in Table S5. If tests showed significant similarities at the 0.05 significance level with another habitat across a variable they were assigned the same letter.

Table 1. Intercept $( \pm \mathrm{SE})$, slope $( \pm \mathrm{SE})$, correlation coefficient $\left(r^{2}\right), F$ statistics $(F)$ and $p$ values $(p)$ of linear regressions of rTA versus rDIC for different subsets of coastal observations. This table complements the results displayed in Fig. 8.

\begin{tabular}{lrrrrr}
\hline Data subset & Intercept & Slope & $r^{2}$ & $F$ & $p$ \\
\hline Transition water & $-24.6( \pm 7.5)$ & $0.91( \pm 0.17)$ & 0.29 & 27.8 & $<0.001$ \\
Coral reef & $-11.3( \pm 6.1)$ & $0.39( \pm 0.13)$ & 0.08 & 8.55 & 0.004 \\
Seagrass meadow: time series & $-71.4( \pm 20.8)$ & $0.73( \pm 0.11)$ & 0.60 & 45.26 & $<0.001$ \\
Seagrass meadow: spatial & $-81.9( \pm 12.4)$ & $0.36( \pm 0.09)$ & 0.32 & 15.8 & $<0.001$ \\
Mangrove forest: time series & $-98.7( \pm 13.2)$ & $0.62( \pm 0.07)$ & 0.79 & 77.26 & $<0.001$ \\
Mangrove forest: spatial & $-113.2( \pm 13.4)$ & $0.60( \pm 0.05)$ & 0.92 & 161.8 & $<0.001$ \\
& & $(0.86$ with inland stands $)$ & & &
\end{tabular}

ows and coral reefs (Guannel et al., 2016). More support for the latter can be found in time series observations, with TA and DIC at the mangrove forest station conforming closely to those at the seagrass meadow station, whilst also displaying erratic deviations towards high rTA and rDIC that varies similarly to other mangrove forest sites (Figs. 7-8). A nega- tive rTA intercept is observed in the mangrove forests' linear relationship between rTA and rDIC (Fig. 8e), which is consistent with a basin-wide cumulative cross-shelf calcification signal, inherited from upstream coral reefs and potentially even seagrass meadows. 

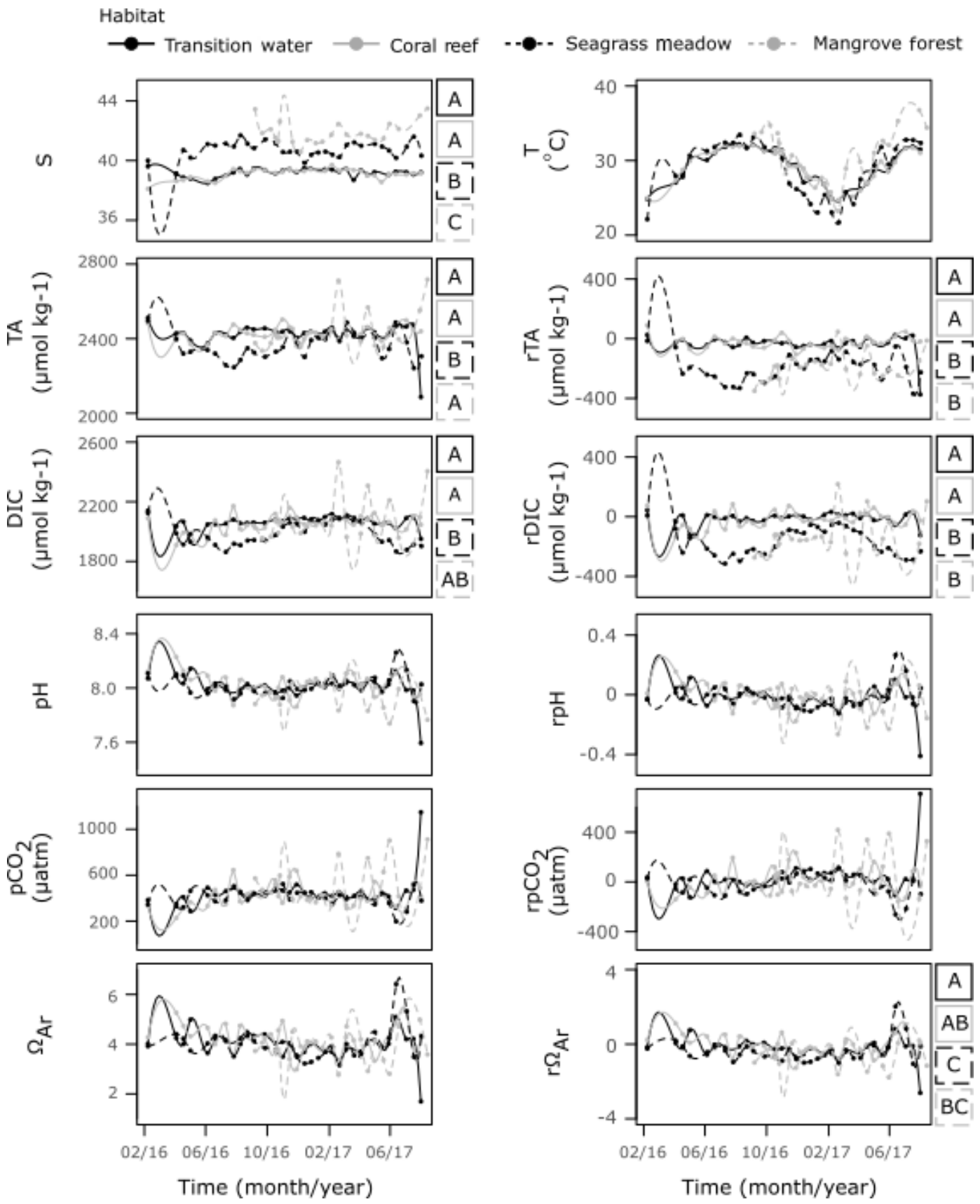

Figure 7. Time series observations of $S, T$, carbonate parameters and non-conservative carbonate system residuals collected from the four time series stations. Observations are shown fitted with a spline function of the order of 100 by the method of Forsythe et al. (1977). For variables which displayed a significant result for WR-ANOVA tests for differences in medians across habitat groups, results from post hoc bootstrapped $t$ tests are shown as letters $(\mathrm{A}-\mathrm{C})$ to the right of the plot. If tests showed significant similarities at the 0.05 significance level with another habitat across a variable, they were assigned the same letter.

These results suggest that the carbonate system and contributions to air-sea $\mathrm{CO}_{2}$ exchanges of overlying waters in Red Sea mangrove forests are likely significantly mediated by water residence time and mixing, not only by metabolic rates. The inland mangrove forest sampled contained drastically higher TA and DIC in surrounding waters. This resulted in higher $p \mathrm{CO}_{2}$ and a large $\mathrm{CO}_{2}$ source to the atmosphere, compared to coastally residing mangrove forests (Figs. S2$\mathrm{S} 3)$. De-gassing of $\mathrm{CO}_{2}$, an increase in calcium carbonate dissolution due to decrease in $\mathrm{pH}$ or an increase in redox processes due to oxygen depletion is most likely the cause for the ratio of rTA : rDIC deviating at this site to an almost 


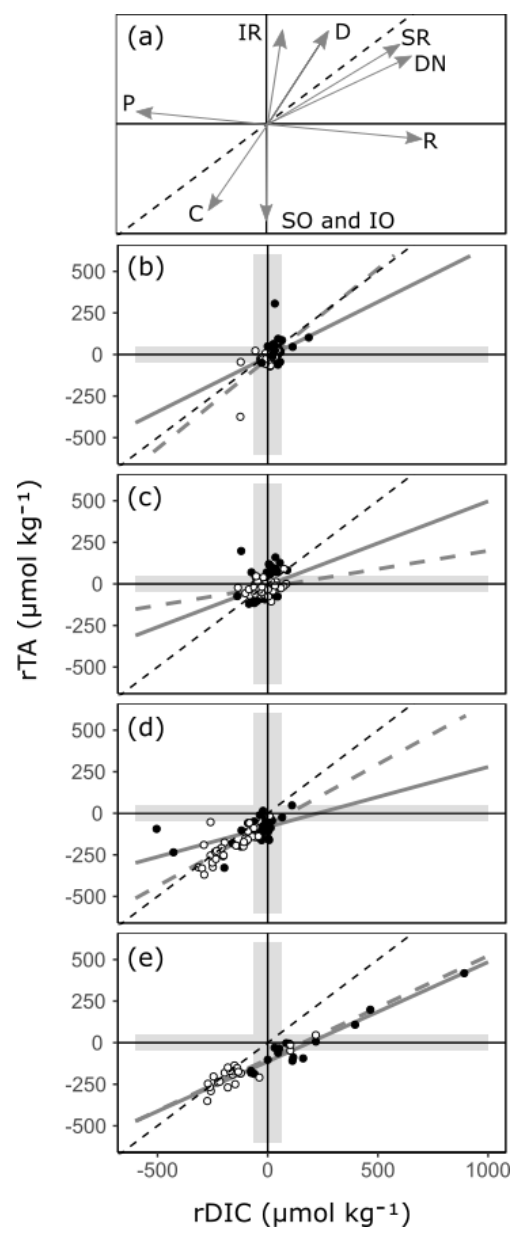

Figure 8. A reference plot (a) showing unitless directional vectors of change in the rTA vs. rDIC space for multiple ecosystem processes. Below, observations of rTA vs. rDIC from transition water and the three coastal habitats are presented: (b) transition water, (c) coral reef, (d) seagrass meadow and (e) mangrove forest. Time series observations are indicated with open circles, and all other spatial data are indicated with closed circles. A $1: 1$ reference line is shown in all plots (black dashed line) as well as regression lines $\left(r^{2}>0.6\right)$ for the time series subset (grey dashed line) and the spatial subset (grey solid line). The reference plot includes directional vectors for calcium carbonate precipitation $(C)$, calcium carbonate dissolution $(D)$, primary production $(P)$, respiration $(R)$, iron reduction (IR), sulfate reduction (SR), denitrification (DN), sulfur oxidation (SO) and iron oxidation (IO). The shaded envelope represents the calculated $99 \%$ PI for rTA and rDIC. An expanded version of panel (e) showing inland mangrove stands is presented in Fig. S2b.

perfect $1: 1$ ratio, from the 0.61 observed elsewhere. This implies that the carbonate system in stagnant water columns over mangrove forests could be different to what is observed in those with variable water exchanges, and the flushing of mangrove forests from surrounding waters can vastly reduce their contribution to air-sea $\mathrm{CO}_{2}$ exchanges. As such, the control of surrounding water exchanges and water residence times should be considered further in these ecosystems, as studies often quantify the influence of mangrove forests on air-sea $\mathrm{CO}_{2}$ exchange using stagnant water columns (Borges et al., 2003; Bouillon et al., 2007, 2008; Macklin et al., 2019; Sea et al., 2018).

Red Sea seagrass meadows have a high species diversity (Qurban et al., 2019; Kenworthy et al., 2007) and show large ecosystem-driven anomalies in rTA and rDIC, but they vary in the balance of ecosystem processes between sites (Fig. 8). Within one site, the time series station, a slope of 0.73 is observed, whilst across other sites no strong relationship is found. The variability between rTA and rDIC between sites and the lack of a significant linear relationship indicate that the balance between ecosystem processes is important in driving the carbonate system of Red Sea seagrass meadows, in combination with metabolic rates and residence times. This is a finding that has been confirmed in separate studies, with the balance of ecosystem processes often effected by variable seagrass meadow density and site oxygenation (Burdige and Zimmerman, 2002; Krumins et al., 2013; Unsworth et al., 2012). Indeed, some seagrass meadow sites visited in the present study have highly variable and species-dependent metabolic rates (Anton et al., 2020). The slope observed at the seagrass meadow time series site is consistent with the coupling of photosynthesis and sedimentary calcification, promoted by increased $\mathrm{pH}$ due to net autotrophy in seagrass meadows, which has been shown to result in a ratio of $1: 1$ change in rTA : rDIC (Barrón et al., 2006; Burdige and Zimmerman, 2002; Krumins et al., 2013; Lyons et al., 2004; Macreadie et al., 2017; Unsworth et al., 2012). Sedimentary sulfur and iron oxidation, which occur alongside sedimentary calcification in oxygenated environments and higher $\mathrm{pH}$, potentially contribute to the lowering of the rTA : rDIC slope below 1 (Burdige and Zimmerman, 2002; Krumins et al., 2013). However, Red Sea seagrass sediments have been observed to contain low levels of iron, reducing the possibility of iron oxidation (Saderne et al., 2020; Anton et al., 2020). At the time series station, lower TA and DIC in summer months is due to a combination of increased metabolic rates and/or residence times.

Due to small perturbations in the carbonate system exhibited by transition waters and coral reefs and the uncertainty limits of our model, little can be concluded about the large-scale variability in ecosystem processes in these habitats. Transition waters show few occurrences of ecosystem anomalies inherited from surrounding coastal habitats. Small temporal variations in rTA and rDIC at the coral reef time series station show no linear relationship or seasonal cycle, consistent with variability driven by exchanges through the complex reef system rather than inherent ecosystem processes and metabolic rate. Spatial variability shows similar characteristics, which can be attributed to a combination of spatial changes in ecosystem processes, residence times, metabolic rates and connectivity (Cyronak et al., 2018; Gattuso et al., 1999; Kleypas et al., 2011; Takeshita et al., 2018). 
What can be concluded is that coral reef and transition waters have little consequence for air-sea carbon fluxes on a local scale, offering little change in the carbonate system compared to offshore conditions (Figs. 4; 6).

The results reported here can offer further explanations to the decadal changes in calcification rates in the Red Sea reported by Steiner et al. (2018), which are also supported within this study (Fig. 3). Steiner et al. (2018) reported a $26 \pm 16 \%$ decline in total calcium carbonate deposition rate along the basin between 1998 and 2018, concentrated in the southern Red Sea, suggesting that coral reefs in the southern Red Sea are under stress. Warming of the Red Sea has been faster than the global average (Chaidez et al., 2017). This warming has been reported to reduce coral growth rates (Cantin et al., 2010), have induced massive bleaching of Red Sea corals south of $20^{\circ} \mathrm{N}$ in the summer of 2015 (Hughes et al., 2018; Osman et al., 2018) and lead to the replacement of coral by algal turf. Indeed, this may have reduced carbonate deposition rates in the southern Red Sea over a basin scale; however, our analysis suggests additional contributions to the decline of calcium carbonate deposition in the Red Sea. In particular, mangrove habitats are characterised here as important sites of TA input, likely driven by carbonate dissolution. Hence, the $13 \%$ increase in mangrove forests in the Red Sea since 1972 (Almahasheer et al., 2016) could also be reflected in increased rates of carbonate dissolution basin-wide.

\section{Conclusion}

We observed strong evidence of ecosystem-driven perturbations in the carbonate system over Red Sea coastal habitats. We employed a simple single-end-member mixing model to estimate the expected conservative behaviour over the coastal zone of the Red Sea. We find that (1) along-shelf changes in TA and DIC exhibit strong linear relationships that are consistent with net basin-scale calcium carbonate precipitation; (2) ecosystem-driven changes in TA and DIC are larger than offshore variations in $>70 \%$ of sampled seagrass meadows and mangrove forests, changes which are influenced by a combination of longer water residence times and community metabolic rates; and (3) the sampled mangrove forests show strong and consistent contributions from both organic respiration and other sedimentary processes (carbonate dissolution and secondary redox processes), while seagrass meadows display more variability in the relative contributions of photosynthesis and other sedimentary processes (carbonate precipitation and oxidative processes). With the available data we cannot conclude if differences in magnitude of rTA and rDIC within habitats reflect differences in residence times or metabolic rates. The results of this study highlight the importance of resolving the influences of water residence times, mixing and upstream habitats on mediating the car- bonate system and coastal air-sea $\mathrm{CO}_{2}$ fluxes over coastal habitats in the Red Sea.

Code availability. Code for the calculation of the Wilcox robust ANOVA post hoc test can be found in the Supplement. All other code relating to figures and analysis was constructed in $\mathrm{R}$ (version 3.4.3) and is available upon request to the corresponding author.

Data availability. The full dataset used in this study can be obtained from PANGAEA (https://doi.pangaea.de/10.1594/ PANGAEA.899850; Baldry et al., 2019).

Supplement. The supplement related to this article is available online at: https://doi.org/10.5194/bg-17-423-2020-supplement.

Author contributions. KB collected a portion of the KAUST samples, performed most of the sample analysis on KAUST samples, performed data analysis, developed conceptual ideas and wrote the manuscript. VS collected a portion of the KAUST samples, performed some sample analysis on KAUST samples and contributed to manuscript preparation. DCM and JHC collected and analysed WHOI samples and contributed to concept development and manuscript preparation. SA facilitated the collection of samples at three time series stations. CMD contributed to the concept development and to manuscript preparation.

Competing interests. The authors declare that they have no conflict of interest.

Acknowledgements. This research was funded by King Abdullah University of Science and Technology (KAUST) through baseline funding and competitive centre funding to Carlos M. Duarte, and Susana Agusti (BAS/1/1071-01-01; BAS/1/1072-01-01). The sample collection and laboratory analysis of KAUST observations was carried out by Kimberlee Baldry and Vincent Saderne. The sample collection and laboratory analysis of Woods Hole Oceanographic Institution (WHOI) observations was supported by award nos. USA-00002, KSA-00011 and KSA-00011/02 made by KAUST to WHOI. Financial support for Daniel C. McCorkle during preparation of the manuscript was provided by the Investment in Science fund at WHOI. We thank all of the contributors who were responsible for collecting and managing Red Sea data that were openly sourced. The full dataset used in this study can be obtained from PANGAEA (https://doi.org/10.1594/PANGAEA.899850). Supplementary tables and figures can be found in the Supplement accompanying this paper. We thank Amr K. Gusti, Andrea Anton, Micheal L. Berumen, Paloma Carrillo-de-Albornoz, Darren J. Cocker, Neus GarciasBonet, Cecilia K. Martin, Juan Martinez-Ayala and Sebastian Overmans for their help and support in sample collection and CTD deployments towards this study. Finally, we thank Zvi Steiner and the 
one anonymous reviewer for their useful comments that contributed to the development of the paper.

Financial support. This research has been supported by the King Abdullah University of Science and Technology (KAUST) (grant nos. BAS/1/1071-01-01 and BAS/1/1072-01-01) and the Investment in Science fund at WHOI.

Review statement. This paper was edited by Stefano Ciavatta and reviewed by Zvi Steiner and one anonymous referee.

\section{References}

Albright, R., Langdon, C., and Anthony, K. R. N.: Dynamics of seawater carbonate chemistry, production, and calcification of a coral reef flat, central Great Barrier Reef, Biogeosciences, 10, 6747-6758, https://doi.org/10.5194/bg-10-6747-2013, 2013.

Almahasheer, H., Aljowair, A., Duarte, C. M., and Irigoien, X.: Decadal stability of Red Sea mangroves, Estuar. Coast. Shelf S., 169, 164-172, https://doi.org/10.1016/j.ecss.2015.11.027, 2016.

Anderson, L. and Dyrssen, D.: Alkalinity and total carbonate in the Arabian Sea. Carbonate depletion in the Red Sea and Persian Gulf, Mar. Chem., 47, 195-202, https://doi.org/10.1016/03044203(94)90019-1, 1994.

Anton, A., Baldry, K., Coker, D., and Duarte, C. M.: Thermal optima and drivers of the low meetabolic rates of seagrass meadows in the Red Sea, Frontiers in Marine Science, in review, 2020.

Baldry, K., Saderne, V., McCorkle, D. C., Churchill, J. H., Agustí, S., and Duarte, C. M.: Surface Carbonate Chemistry of the Red Sea (offshore and coastal), PANGAEA, https://doi.org/10.1594/PANGAEA.899850, 2019.

Barrón, C., Duarte, C. M., Frankignoulle, M., and Borges, A. V.: Organic carbon metabolism and carbonate dynamics in a Mediterranean seagrass (Posidonia oceanica), meadow, Estuar. Coast., 29, 417-426, https://doi.org/10.1007/BF02784990, 2006.

Bauer, J. E., Cai, W.-J., Raymond, P. A., Bianchi, T. S., Hopkinson, C. S., and Regnier, P. A.: The changing carbon cycle of the coastal ocean, Nature, 504, 61-70, https://doi.org/10.1038/nature12857, 2013.

Bouillon, S., Middelburg, J. J., Dehairs, F., Borges, A. V., Abril, G., Flindt, M. R., Ulomi, S., and Kristensen, E.: Importance of intertidal sediment processes and porewater exchange on the water column biogeochemistry in a pristine mangrove creek (Ras Dege, Tanzania), Biogeosciences, 4, 311-322, https://doi.org/10.5194/bg-4-311-2007, 2007.

Bouillon, S., Borges, A. V., Castañeda-Moya, E., Diele, K., Dittmar, T., Duke, N. C., Kristensen, E., Lee, S. Y., Marchand, C., and Middelburg, J. J.: Mangrove production and carbon sinks: a revision of global budget estimates, Global Biogeochem. Cy., 22, GB2013, https://doi.org/10.1029/2007GB003052, 2008.

Borges, A. V., Djenidi, S., Lacroix, G., Théate, J., Delille, B., and Frankignoulle, M.: Atmospheric $\mathrm{CO}_{2}$ flux from mangrove surrounding waters, Geophys. Res. Lett., 30, 1558, https://doi.org/10.1029/2003gl017143, 2003.

Burdige, D. J. and Zimmerman, R. C.: Impact of sea grass density on carbonate dissolution in $\mathrm{Ba}$ - hamian sediments, Limnol. Oceanogr., 47, 1751-1763, https://doi.org/10.4319/lo.2002.47.6.1751, 2002.

Burkholz, C., Duarte, C. M., and Garcias-Bonet, N.: Thermal dependence of seagrass ecosystem metabolism in the Red Sea, Mar. Ecol.-Prog. Ser., 614, 79-90, 2019.

Camp, E. F., Suggett, D. J., Gendron, G., Jompa, J., Manfrino, C., and Smith, D. J.: Mangrove and Seagrass Beds Provide Different Biogeochemical Services for Corals Threatened by Climate Change, Front. Mar. Sci., 3, 1-16, https://doi.org/10.3389/fmars.2016.00052, 2016.

Cantin, N. E., Cohen, A. L., Karnauskas, K. B., Tarrant, A. M., and McCorkle, D. C.: Ocean warming slows coral growth in the central Red Sea, Science, 329, 322-325, https://doi.org/10.1126/science.1190182, 2010.

Chaidez, V., Dreano, D., Agusti, S., Duarte, C. M., and Hoteit, I.: Decadal trends in Red Sea maximum surface temperature, Sci. Rep.-UK, 7, 1-8, https://doi.org/10.1038/s41598-017-08146-z, 2017.

Challener, R. C., Robbins, L. L., and McClintock, J. B.: Variability of the carbonate chemistry in a shallow, seagrassdominated ecosystem: implications for ocean acidification experiments, Mar. Freshwater Res., 67, 163-172, https://doi.org/10.1071/MF14219, 2016.

Churchill, J. H., Bower, A. S., McCorkle, D. C., and Abualnaja, Y.: The transport of nutrient-rich Indian Ocean water through the Red Sea and into coastal reef systems, J. Mar. Res., 72, 165-181, https://doi.org/10.1357/002224014814901994, 2014.

Cook, R. D. and Weisberg, S.: Graphics for assessing the adequacy of regression models, J. Am. Stat. Assoc., 92, 490-499, https://doi.org/10.2307/2965698, 1997.

Cyronak, T., Andersson, A. J., Langdon, C., Albright, R., Bates, N. R., Caldeira, K., Carlton, R., Corredor, J. E., Dunbar, R. B., and Enochs, I.: Taking the metabolic pulse of the world's coral reefs, PloS One, 13, e0190872, https://doi.org/10.1371/journal.pone.0190872, 2018.

de Vries, A. J., Tyrlis, E., Edry, D., Krichak, S. O., Steil, B., and Lelieveld, J.: Extreme precipitation events in the Middle East: Dynamics of the Active Red Sea Trough, J. Geophys. Res.Atmos., 118, 7087-7108, https://doi.org/10.1002/jgrd.50569, 2013.

Dickson, A. G., Sabine, C. L., and Christian, J. R.: Guide to best practices for ocean $\mathrm{CO}_{2}$ measurements, PICED Special Publication 3, IOCCP Report No. 8, North Pacific Marine Science Organization, Sidney, Canada, 2007.

Doney, S. C.: The growing human footprint on coastal and open-ocean biogeochemistry, Science, 328, 1512-1516, https://doi.org/10.1126/science.1185198, 2010.

Duarte, C. M., Hendriks, I. E., Moore, T. S., Olsen, Y. S., Steckbauer, A., Ramajo, L., Carstensen, J., Trotter, J. A., and McCulloch, M.: Is ocean acidification an open-ocean syndrome? Understanding anthropogenic impacts on seawater $\mathrm{pH}$, Estuar. Coast., 36, 221-236, https://doi.org/10.1007/s12237-013-9594-3, 2013.

Forsythe, G. E., Malcolm, M. A., and Moler, C. B.: Computer Methods for Mathematical Computations, Prentice Hall Professional Technical Reference, Wiley, 259 pp., 1977.

Gattuso, J.-P., Frankignoulle, M., and Wollast, R.: Carbon and Carbonate Metabolism in Coastal Aquatic Ecosystems, Annu. Rev. Ecol. Syst., 29, 405-434, https://doi.org/10.1146/annurev.ecolsys.29.1.405, 1998. 
Gattuso, J.-P., Allemand, D., and Frankignoulle, M.: Photosynthesis and calcification at cellular, organismal and community levels in coral reefs: a review on interactions and control by carbonate chemistry, Am. Zool., 39, 160-183, https://doi.org/10.1093/icb/39.1.160, 1999.

Gattuso, J.-P., Epitalon, J.-M., Lavigne, H., and Orr, J.: seacarb: Seawater Carbonate Chemistry, R package version 3.2.6, available at: https://CRAN.R-project.org/package=seacarb (last access: 3 May 2019), 2018.

Giraud, X., Le Quéré, C., and Da Cunha, L. C.: Importance of coastal nutrient supply for global ocean biogeochemistry, Global Biogeochem. Cy., 22, GB2025, https://doi.org/10.1029/2006GB002717, 2008.

Guannel, G., Arkema, K., Ruggiero, P., and Verutes, G.: The power of three: coral reefs, seagrasses and mangroves protect coastal regions and increase their resilience, PloS one, 11, e0158094, https://doi.org/10.1371/journal.pone.0158094, 2016.

Hijmans, R. J.: geosphere: Spherical Trigonometry, R package version 1.5-7, available at: https://CRAN.R-project.org/package= geosphere (last access: 14 May 2018), 2017.

Ho, D. T., Ferrón, S., Engel, V. C., Larsen, L. G., and Barr, J. G.: Air-water gas exchange and $\mathrm{CO}_{2}$ flux in a mangrove-dominated estuary, Geophys. Res. Lett., 41, 108-113, https://doi.org/10.1002/2013g1058785, 2014.

Hughes, T. P., Anderson, K. D., Connolly, S. R., Heron, S. F., Kerry, J. T., Lough, J. M., Baird, A. H., Baum, J. K., Berumen, M. L., Bridge, T. C., Claar, D. C., Eakin, C. M., Gilmour, J. P., Graham, N. A. J., Harrison, H., Hobbs, J.-P. A., Hoey, A. S., Hoogenboom, M., Lowe, R. J., McCulloch, M. T., Pandolfi, J. M., Pratchett, M., Schoepf, V., Torda, G., and Wilson, S. K.: Spatial and temporal patterns of mass bleaching of corals in the Anthropocene, Science, 359, 80-83, https://doi.org/10.1126/science.aan8048, 2018.

Hydes, D., Jiang, Z., Hartman, M., Campbell, J., Pagnani, M., and Kelly-Gerreyn, B.: Surface DIC and TALK measurements along the M/V Pacific Celebes VOS Line during the 2007-2012 cruises, Carbon Dioxide Information Analysis Center. Oak Ridge National Laboratory, US Department of Energy, Oak Ridge, Tennessee, https://doi.org/10.3334/CDIAC/OTG.VOS_PC_20072012, 2012.

IPCC: Climate change 2013: The physical science basis: Working Group I contribution to the Fifth assessment report of the Intergovernmental Panel on Climate Change: Cambridge University Press, Cambridge, UK, https://doi.org/10.1017/CBO9781107415324, 2014.

Jiang, Z. P., Tyrrell, T., Hydes, D. J., Dai, M., and Hartman, S. E.: Variability of alkalinity and the alkalinity-salinity relationship in the tropical and subtropical surface ocean, Global Biogeochem. Cy., 28, 729-742, https://doi.org/10.1002/2013GB004678, 2014.

Kenworthy, W. J., Wyllie-Echeverria, S., Coles, R. G., Pergent, G., and Pergent-Martini, C.: Seagrass conservation biology: an interdisciplinary science for protection of the seagrass biome, in: Seagrasses: Biology, Ecology and Conservation, Springer, Dordrecht, 595-623, https://doi.org/10.1007/978-1-4020-29837_25, 2007.

Kleypas, J. A., Anthony, K. R., and Gattuso, J. P.: Coral reefs modify their seawater carbon chemistry-case study from a barrier reef (Moorea, French Polynesia), Glob. Change Biol., 17, 36673678, https://doi.org/10.1111/j.1365-2486.2011.02530.x, 2011.
Krumgalz, B., Erez, J., and Chen, C.: Anthropogenic $\mathrm{CO}_{2}$ penetration in the northern Red Sea and in the Gulf of Elat (Aqaba), Oceanol. Acta, 13, 283-290, 1990.

Krumins, V., Gehlen, M., Arndt, S., Van Cappellen, P., and Regnier, P.: Dissolved inorganic carbon and alkalinity fluxes from coastal marine sediments: model estimates for different shelf environments and sensitivity to global change, Biogeosciences, 10 , 371-398, https://doi.org/10.5194/bg-10-371-2013, 2013.

Lyons, T. W., Walter, L. M., Gellatly, A. M., Martini, A. M., and Blake, R. E.: Sites of anomalous organic remineralization in the carbonate sediments of South Florida, USA: the sulfur cycle and carbonate-associated sulfate, Geol. S. Am. S., 379, 161-176, https://doi.org/10.1130/0-8137-2379-5.161, 2004.

Macklin, P. A., Suryaputra, I. G. N. A., Maher, D. T., Murdiyarso, D., and Santos, I. R.: Drivers of $\mathrm{CO}_{2}$ along a mangrove-seagrass transect in a tropical bay: Delayed groundwater seepage and seagrass uptake, Cont. Shelf Res., 172, 57-67, https://doi.org/10.1016/j.csr.2018.10.008, 2019.

Macreadie, P. I., Serrano, O., Maher, D. T., Duarte, C. M., and Beardall, J.: Addressing calcium carbonate cycling in blue carbon accounting, Limnol. Oceanogr. Lett., 2, 195-201, https://doi.org/10.1002/lol2.10052, 2017.

Mair, P. and Wilcox, R.: WRS2: Wilcox robust estimation and Testing, $\mathrm{R}$ package ver 3.4.4, available at: https://cran.r-project.org/ web/packages/WRS2/index.html, last access: 1 October 2018.

Meister, P.: Two opposing effects of sulfate reduction on carbonate precipitation in normal marine, hypersaline, and alkaline environments, Geology, 41, 499-502, 2013.

Middelburg, J. J., Nieuwenhuize, J., Slim, F. J., and Ohowa, B.: Sediment biogeochemistry in an East African mangrove forest (Gazi bay, Kenya), Biogeochemistry, 34, 133-155, 1996.

Millero, F. J.: Carbonate constants for estuarine waters, Mar. Freshwater Res., 61, 139-142, https://doi.org/10.1071/MF09254, 2010.

Osman, E. O., Smith, D. J., Ziegler, M., Kürten, B., Conrad, C., El-Haddad, K. M., Voolstra, C. R. and Suggett, D. J.: Thermal refugia against coral bleaching throughout the northern Red Sea, Glob. Change Biol., 24, e474-e484, https://doi.org/10.1111/gcb.13895, 2018.

Papaud, A. and Poisson, A.: Distribution of dissolved $\mathrm{CO}_{2}$ in the Red Sea and correlations with other geochemical tracers, J. Mar. Res., 44, 385-402, https://doi.org/10.1357/002224086788405347, 1986.

Picheral, M., Searson, S., Taillandier, V., Bricaud, A., Boss, E., Ras, J., Claustre, H., Ouhssain, M., Morin, P., Tremblay, J., Coppola, L., Gattuso, J., Metzl, N., Thuillier, D., Gorsky, G., Tara Oceans Consortium (Coordinators), and Tara Oceans Expedition (Participants): Vertical profiles of environmental parameters measured on discrete water samples collected with Niskin bottles during the Tara Oceans expedition 2009-2013, PANGAEA, https://doi.org/10.1594/PANGAEA.836319, 2014.

Qurban, M. A. B., Karuppasamy, M., Krishnakumar, P. K., GarciasBonet, N., and Duarte, C. M.: Seagrass Distribution, Composition and Abundance Along the Saudi Arabian Coast of Red Sea, in: Oceanographic and Biological Aspects of the Red Sea, edited by: Rasul, N. M. A., and Stewart, I. C. F., Springer, Cham, 367385, https://doi.org/10.1007/978-3-319-99417-8_20, 2019.

R Core Team: R v3.4.3, Vienna, Austria, https://www.R-project. org/, last access: 8 March 2018. 
Robbins, P. E.: Oceanic carbon transport carried by freshwater divergence: Are salinity normalizations useful?, J. Geophys. Res.-Oceans, 106, 30939-30946, https://doi.org/10.1029/2000JC000451, 2001.

Saderne, V., Baldry, K., Anton, A., Agustí, S., and Duarte, C. M.: Characterization of the $\mathrm{CO}_{2}$ system in a coral reef, a seagrass meadow, and a mangrove forest in the central Red Sea, J. Geophys. Res.-Oceans, 124, 7513-7528, https://doi.org/10.1029/2019JC015266, 2019.

Sea, M. A., Garcias-Bonet, N., Saderne, V., and Duarte, C. M.: Carbon dioxide and methane fluxes at the air-sea interface of Red Sea mangroves, Biogeosciences, 15, 5365-5375, https://doi.org/10.5194/bg-15-5365-2018, 2018.

Sofianos, S. S. and Johns, W. E.: An oceanic general circulation model (OGCM) investigation of the Red Sea circulation: 2. Three-dimensional circulation in the Red Sea, J. Geophys. Res.-Oceans, 108, 3066, https://doi.org/10.1029/2001JC001185, 2003.

Steiner, Z., Erez, J., Shemesh, A., Yam, R., Katz, A., and Lazar, B.: Basin-scale estimates of pelagic and coral reef calcification in the Red Sea and Western Indian Ocean, P. Natl. Acad. Sci. USA, 111, 16303-16308, https://doi.org/10.1073/pnas.1414323111, 2014.

Steiner, Z., Turchyn, A. V., Harpaz, E., and Silverman, J.: Water chemistry reveals a significant decline in coral calcification rates in the southern Red Sea, Nat. Commun., 9, 3615, https://doi.org/10.1038/s41467-018-06030-6, 2018.

Takeshita, Y. T., Cyronak, T., Martz, T. R., Kindeberg, T., and Andersson, A. J.: Coral reef carbonate chemistry variability at different functional scales, Front. Mar. Sci., 5, 175, https://doi.org/10.3389/fmars.2018.00175, 2018.
Unsworth, R. K., Collier, C. J., Henderson, G. M., and McKenzie, L. J.: Tropical seagrass meadows modify seawater carbon chemistry: implications for coral reefs impacted by ocean acidification, Environ. Res. Lett., 7, 024026, https://doi.org/10.1088/1748-9326/7/2/024026, 2012.

Wafar, M., Ashraf, M., Manikandan, K. P., Qurban, M. A., and Kattan, Y.: Propagation of Gulf of Aden Intermediate Water (GAIW) in the Red Sea during autumn and its importance to biological production, J. Marine Syst., 154, 243-251, https://doi.org/10.1016/j.jmarsys.2015.10.016, 2016.

Wurgaft, E., Steiner, Z., Luz, B., and Lazar, B.: Evidence for inorganic precipitation of $\mathrm{CaCO}_{3}$ on suspended solids in the open water of the Red Sea, Mar. Chem., 186, 145-155, https://doi.org/10.1016/j.marchem.2016.09.006, 2016.

Zablocki, J. A., Andersson, A. J., and Bates, N. R.: Diel aquatic $\mathrm{CO}_{2}$ system dynamics of a Bermudian mangrove environment, Aquat. Geochem., 17, 841, https://doi.org/10.1007/s10498-0119142-3, 2011.

Zeebe, R. E. and Wolf-Gladrow, D. A.: $\mathrm{CO}_{2}$ in seawater: Equilibrium, kinetics, isotopes, Elsevier Oceanography Series, 65, Elsevier, 1-136, 2001.

Zhan, P., Subramanian, A. C., Yao, F., and Hoteit, I.: Eddies in the Red Sea: A statistical and dynamical study, J. Geophys. Res.-Oceans, 119, 3909-3925, https://doi.org/10.1002/2013JC009563, 2014. 